PIETER A. M. SEUREN

\title{
FORMAL THEORY AND THE ECOLOGY OF LANGUAGE
}

\begin{abstract}
Address delivered on occasion of the official inauguration of the Max-Planck-Institut für Psycholinguistik at Nijmegen, April 18th, 1986.*
\end{abstract}

Ladies and gentlemen,

0 .

When, just under a decade ago, what is now the Max Planck Institute for Psycholinguistics started operating in Nijmegen, it latched on neatly to the new developments that were taking place in cognitive psychology and that originated largely in the United States of America. After, roughly, 1960 behaviourism had been waning rapidly after a period of over forty years, in which it had transformed psychology into a relatively exact science, where questions of the causality of human behaviour could be formulated with much greater clarity than before. Following a good old maxim in scientific methodology, behaviourism had confined itself to a set of absolutely minimal assumptions regarding behavioural causation: behaviour was taken to be caused exclusively either by direct physical stimulation or by association of stimuli. Essentially, no other assumption about the behaving organism, in so far as it was inaccessible to scientific observation, was made than that stimuli can stand in for each other provided there have been a sufficient

This text is a slightly adapted version of the speech as it was actually pronounced. A few paragraphs, which related too specifically to matters of internal or local interest, have been omitted, and, given the less strict limitations of length in the printed version, one or two central viewpoints have been further elaborated and illustrated. 
number of temporally contiguous occurrences. Although this general assumption did not turn out to be false, it proved abysmally inadequate. During the ' 50 s it became clear that behaviourism had been operating within the constraints of a theory that was far too restricted and far too poor to be even remotely adequate. It was felt, in the early '60s, that an entirely new orientation was called for. Psychology had lost its bearings and was looking for a new and richer set of basic assumptions. This led to what we now know as the new Cognitive Psychology. The differences between the old behaviouristic paradigm and the new one are very profound. What was involved was far more than a simple admission that the old set of basic assumptions had been too restricted, so that a more liberal attitude should be taken with regard to the axioms of psychological theory construction. What was at issue were fundamental questions abount the human mind, and, therefore, questions of the nature of mankind and its position in the world. There was a deep and abrupt abyss between the old and the new schools, an abyss that involved philosophies and personalities.

1.

But what I want to call attention to now is one particular central feature of this change of paradigms, the fact, that is, that the notion of automatized algoritbmic calculus became an integral part of the new cognitive approach. This was something behaviourism had never taken into account (or always rejected): the idea that the brain performs a gigantic amount of fully automatized formal calculus as part of any kind of mental activity. The mind, or whatever term one preferred to refer to the ensemble of causal factors allegedly responsible for the totality of human behaviour, was no longer seen as a general purpose apparatus responding solely to stimuli, either by immediate physiological stimulation or by association of stimuli. From now on, the mind was looked upon as something involving at least an enormous computing plant, and perhaps a great deal else the nature of which has not, so far, been disclosed. In this new perspective it seemed best to concentrate upon this notion of algorithmic procedure and get as much mileage out of it as at all possible, leaving those aspects of mental activity that still do not look like being implementable in the guise of some computing programme to a, hopefully happier, future.

This is our present perspective. To use Fodor's frame of reference, ${ }^{1}$ 
we distinguish, in principle, between a central processing unit and 'modules' or highly specific channels conveying and converting peripheral, often environmental, input to the central system, and, in so far as output channels are concerned, converting structured input from the central unit to outwardly directed commands, often resulting in behaviour. Each of the senses is thought to have its own specific module, operating beween sensory input and interpretable central output. Language is likewise taken to be channeled through an autonomous module, linked up in specific ways with sensory channels and motor command systems. The linguistic module is a two-way channel, serving for incoming linguistic material in what is called comprehension, as well as for outgoing material in production. The processes of conversion, or transformation, that are thought to take place inside the module or channel, are entirely automatized and beyond any possible awareness. We like to think of these linguistic processes as the psychological grammar of the language user.

The central processing unit is, in a way, a clearinghouse for all information that comes in or goes out. It is here that the necessary integration of all information available is thought to take place. And this is also the mental compartment that is open to awareness, introspection, and, to a considerable extent, control. All operations of this unit are stored in Memory or Knowledge, which makes for high operating costs, in terms of both operating time and operating space.

This picture is no doubt far too simplistic and too general. The essentialpoint, however, is thatadistinction is madebetween themoreorlessperipheral afferent and efferent systems that are fully automatized and beyond awareness or introspection on the one hand, and 'higher' integrative and creative functions or 'powers'muchclosertothephenomenological'ego' on theother. Thepointisalso that the main effort in experimental and theoretical psychology is directed at the peripheral automatized modules or channels that we have mentioned and their interface with the central unit, whereby, of course, the psycholinguists have the linguistic channel as their legitimate province. But the precise workings of the centralunitstill remainlargelyoutoffocus. Totheextentthatcentralfunctionsplay aroleincognitivepsychologytheyarinvokedratherthanpreciselyspecified. They still remain, at present, too far beyond our empirical reach to think of sensible experiments of formal hypotheses in this respect. ${ }^{2}$ Fodor, in a recent BBC

2 Some of the activity going on centrally can be trapped experimentally: when the activity level goes up, the eye pupil responds a little later by increasing its size, this indicating greater 'cognitive load' or greater attention. This is, however, little more 
interview, overstated the case a little when he said that present-day cognitive psychologyhardlyoccupies itself with psychologyproper, its main concernat the moment being the peripheral apparatus. But it could not be an overstatement if there were not some truth to it.

This initselfisnotsurprising. On thecontrary, itdefinitely lookslikegood method to start with the reconstruction of those elements that are closest to empirical and verifiable reality, and thus work one's way inwards: once we have reliable theories about the form and structure of the interfaces of the various modules with the central unit we will be entitled to take these as basic verification material and start a second phase of theory building, relating to the central unit.

2.

Given these concerns, goals and methods, it is inevitable that contact is sought and established with the other disciplines that occupy themselves with the formal analysis of linguistic structures and their sematic interpretation, with formal linguistics, that is, and formal semantics. And here we come to the topic proper of this speech. Present-day cognitive psychology is paradigmatically characterized by the machine analogy, by the notion that cognitive processes occur as, or perhaps even are, calculi, formally defined chains of operations on symbols. Psychology, however, is not the only discipline concerned with language and characterized by analyses in terms of formal calculi. The notion of calculus as an explanatory device in language studies is now generally accepted, also, and perhaps even more, in other disciplines. Given this situation, it would be absurd if notes were not compared. But doing that requires a transgression of traditional disciplinary boundaries and an assimilation of methods, notions and ways of thinking and arguing that are often alien to what one has grown used to at home, and sometimes even incompatible with it. What I want to do now is take a look at some crucial aspects of this situation of interdisciplinary contact over explanatory formal calculi, or, more prestigioulsy, explanatory formal theories.

Psychology is, of course, far from a monolithic whole: it unites projects that range from the phenomenological to the fully machine-

than seeing smoke billowing from a chimney and knowing that the fire in the house is being burned high. We still remain largely ignorant about the internal structures and processes. 
implemented. The internal oppositions in psychology are powerful and important. The phenomenologists, on the one hand, continue to uphold the impenetrability of the central cognitive processes to analyses in terms of formal procedures, saying that such analyses somehow miss the point, if not the depth, of what experience and understanding amount to (and they concentrate largely on the central processes, taking the modular works for granted). The computer boys, on the other hand, united under the flag of Artificial Intelligence, often sound as though in their view nothing is a theory unless it is fully implemented (and they have a preference for the peripheral processes, taking the extrapolation to the central works for granted). Now the section generally known as "cognitive psychology", and in particular psycholinguistics, occupies a position that is clearly left of centre, if $\mathrm{AI}$ is on the left, and phenomenology on the right hand side of this house. In other words, sympathies are in principle with the computational approach, but the philosophical obstacles are not overlooked, nor are less than fully formalized analyses scorned. Yet a full formal specification of the processes involved is, rightly, considered an ideal to be striven for.

In this perspective it is important to realize that the computational element is very recent in psychology, and still far from being properly developed and integrated. Traditionally, and, one may say, essentially, psychology is an ecological science: it studies living organisms in their natural environment. Experiments, involving artifical or laboratory settings, are always subservient to the overall goal of gaining insight into the functioning of the organism in its natural environment. Calculus, or computation, had never, until recently, played a role in explanatory psychological hypotheses. In this respect, the psychologists can hardly fail to lose out on mathematicians and logicians, whose primary concern is precisely the nature, the structure, and the properties of formal calculus, but who have no professional knowledge of or about language. We are thus beginning to detect the contours of a situation of contrast or unbalance: two kinds of expertise are required, let us say an ecological and a formal expertise, but they are each in the province of traditionally unrelated disciplines that are now brought into contact with each other. This naturally leads to a rift. On one side you will find the strict formalists, who bring along a (sometimes preconceived) formal analytical system, and apply that to (some would say: impose it on) language, with no concern for the ecology of language. Yet they do know about the foundations of computational systems, and, when they are semanticists, also about certain sticky peculiarities of natural language when viewed in the light of specifically logical calculi. And on the other side you find the formally minded 
ecologists, who where, so to speak, born and bred in a tradition where the facts of linguistic life are treated with due respect, but where familiarity with formal systems was hardly cultivated. Yet they have begun to require computational strictnes for their theories. Clearly, when, as is now happening, the formalists begin to make claims about language, and the ecologists start to formalize their theories thus making them computationally viable, one may expect a collision.

3.

In order to understand the situation we must be aware of the uncanny power of formal systems in scientific work. No sooner has a formal system been presented on the market than the young researchers scurry around and start applying it with unchecked fervour. This seems to be a fact of academic life, part of the ecology of academe. Schools are quickly formed when a formal apparatus is at hand, but the preparatory work of piecing together the formal system on the basis of countless methodological, philosophical, or empirical considerations does not attract large numbers at all, even though it is no doubt more creative than mere application, - or perhaps precisely because of that. And, what's more, once the tribes of researchers have begun ciphering away, they definitely do not want to be bothered by doubts about the paradigm they work in. This is apparently a feature of the human character. It helps to explain a curious phenomenon that rears its head from time to time in the history of language studies (and perhaps also clscwhere, although I do not know). I am referring to the periodic oppositions between formal analysts and fact-finders, whereby, curiously, the formalists keep cherishing their systems even in the face of crucial counterevidence (they are clearly unwilling to go back to the drawing board). The fact-finders, in so far as they do not reject any formal theory at all (a frequently found but unjustified reaction), feel frustrated at the formalists' riding roughshod over the facts, which are the fact-finders' bread and butter. They would want the formalists to redesign their systems in better accordance with empirical reality.

Such mutual incomprehension existed in ancient times between the schools of analogists and anomalists. The analogists applied contemporary logical analysis, extended with some grammatical apparatus, to the sentences of Greek and Latin. Whatever did not fit their system they declared inessential and due to the moral decay of mankind. The anomalists, on the other hand, were much more impressed by the natural origin of language. They accepted language with all its apparent quirks and irregularities, leaving the 
formulation of a precise formal description to future times, when more adequate insights would have been gained. The crucial difference between these two schools, in so far as we understand the issue today, was that the analogists imposed a largely preconceived system upon the facts of language, whereas the anomalists were more inductivist and hoped, optimistically, that sooner or later the facts observed would find a natural mould in an empirically adequate formal theory. The difference is one of degree: it depends on how soon one feels one is entitled to let loose a formal hypothesis upon the observed facts. The anomalists were more patient, and probably wiser, but they, too, will face the moment where a formal hypothesis is imposed on language. In any case, the dispute was never resolved, mainly because both parties lacked the formal and the empirical resources to get anywhere near a satisfactory synthesis.

What we see nowadys is a repetition of this ancient clash: our 20th century logicians and formal semanticists are latter-day analogists, and the ancient anomalists were representatives of what we now call the ecological view.

4.

Let us take a look now at the details of the modern situation. The disciplines involved are psychology and linguistics on the ecological side, and formal semantics on the formal side. As regards psychology, a rough sketch of that discipline, in relation with the issue at hand, has been given. How does linguistics fit into this? Like psychology, linguistics clearly stands in an ecological tradition. Modern linguistics came about in a context of curiosity with regard to the dynamics, in both an historical and a synchronic sense, of languages as social norm systems. The formalization which is now so prominent in linguistics started relatively recently, first with American structuralism, and then, since the mid-fifties, with the development of generative grammar. Characteristically, as formalization in theory building increased, the ecological conviction got shakier.

Linguistics has never been directly interested in hardware reality the way psychology is. But, given its concern with social norm systems, it has always had a stake in the business of formulating hypothetical software specifications for linguistic structures and processes. This difference is reflected in the fact that the linguist's livelihood does not derive from experiments, as the psychologist's does, but from intuitive data, the so-called 
'judgements'. One may have one's reservations about this state of affairs, but linguists cannot be denied a concern for psychological reality.

There are, of course, many different trends and approaches in modern linguistics. But to the extent that they are more formalized they are also less committed to psychological reality. Developments that came about under the influence of Chomsky have always aimed at full formalization, and we see that attitudes with regard to questions of psychological reality have been characterized all the time by uncertainty, even contradiction, whereby there has been an overall movement from staunch realism to a hesitating epiphenomenalism. Even more significantly, in the highly formalized development of GPSG (Generalized Phrase Structure Grammar), created mainly by Gerald Gazdar and strongly flavoured with mathematics and formal semantics, psycholinguistic relevance, if not reality, was strongly claimed in the earlier papers: there, one key argument in favour of this kind of grammar was derived from its parsing potential (humans both synthesize and parse their sentences in actual use). But now ${ }^{3}$ we read: "Thus we feel it is possible, and arguably proper, for a linguist (qua linguist) to ignore matters of psychology." (The authors remain silent, however, about the ontology for the formal descriptive metalanguage in which GPS-grammars are to be formulated, thus leaving an epistemological gap in their metatheory.)

Linguistics is thus no longer as staunchly ecological as it used to be. In fact, quite a few linguists have begun to make common cause with formal semanticists, attempting to integrate formal semantic with grammatical theories. As mergings of this kind take place the ecological interest decreases and realism is either given up or fatally weakened.

The explanation for this correlation between high degree of formalization and lack of ecological interest is clear: a fully-fledged ecological view necessarily involves many more different parameters than a disembodied strictly formal approach, thus complicating the theorist's task enormously. The pure formalist is interested in his game of symbol manipulation, and he lets in new facts and new parameters only to the extent that this makes his game more exciting: the new facts and parameters are his handicaps, which enable him to show his prowess. But too many handicaps spoils the game. The danger in all this is, of course, that precious energies may turn out to have been wasted in the absence of sufficient methodological security. But we are not to judge on that now. Our present concern is, rather, the question of whether, despite the risks taken, there is sufficient explanatory value in the 
formal systems developed. If all they do is "characterize output", as is often said, - that is, if nothing more is involved than an epiphenomenal interpretation, then they had better not be too intricate or too time-consuming, since a responsible research strategy leaves no room for such frills, especially if, as is unfortunately the case, they dismally fail to "characterize output" anyway. But it is also possible, of course, that the formalisms thought up by our myopic friends are on the right track, or almost. In that case we must take them seriously and invest some of our time and energy in them. And, in any case, in forcing ourselves to 'get into' such formal systems we may acquire some important specific expertise. So the upshot is that we must, anyway, go over and have a good look.

It is generally agreed, but not necessarily correct, that the formal generative systems developed in linguistics have yielded little or nothing in the way of ecological harvest. The optimism of the early ' 60 s made way for a general pessimism, and, as a result, psycholinguists feel rather left to their own devices when it comes to reconstructing actual grammatical processing. I am far from convinced that this pessimism is justified. In fact, I believe that the mismatch between early psycholinguistic experiments and early generative (transformational) linguistic theories was largely due to both a faulty experimental set-up and the immaturity of the linguistic theories in question. But be that as it may, I want to concentrate now on the formal theories constructed not by the linguists but by the formal semanticists, since it is these theories that touch directly on the interface of the linguistic channel with central cognition. So let us have a look at formal semantics, and its ecology.

5.

Formal semantics is the result of applying to natural language the model-theoretic techniques developed in proof theory in mathematical logic. Formal semantics is therefore often equated with model-theoretic semantics. Its origins lie clearly in mathematical logic as known and developed in the 20 th century, including its philosophical context. And it is fundamentally based on the assumption that natural language is a formal language of the type developed and used in modern quantification theory (with intensions): To the extent that language fails to fit this description the formal semanticist is not interested and leaves the investigation to lesser disciplines, such as pragmatics.

The bone of contention between us, ecologists, and the formal sem- 
anticists is the question of the precise demarcation of what is and is not representable, in language, as a formal system. We have no quarrel over the general statement that language is to be seen as a whole of formal structures and procedures. In fact, enough evidence has come to light to show that, for example, an analysis of sentences in terms of modern quantification theory (restricted quantification, that is) yields a notable explanatory profit. But the question is: how much is and how much is not to be captured by logical analysis. It is, in essence, a question of what to do with refractory semantic intuitions: are they to be taken seriously and thus incorporated into a richer and non-standard logical theory, as we propose, or shall we "keep logic standard" and relegate refractory intuitions to some form of pragmatics, as is the typical strategy of formal semanticists? We, like the ancient anomalists, are more demanding and more patient as regards formalization; the formal semanticists, like their ancient analogist counterparts, want to get cracking as quickly as possible.

It must be observed that during this century logic has moved our way a little. Older logicians, such as Russell or Tarski, saw very little of logical value in language. It was their opinion that natural language was, for the most part, vague, ambiguous, unreliable, in short: part of the contaminated world. Russell, prolific and able writer as he was, expressed himself often on this score. He was particularly bitter against the Oxford school of Ordinary Language Philosophy, whose representatives took a strictly ecological view and occasionally dared to criticize Russell's analysis of English sentences, an activity he indulged in sometimes to eke out what little of good logic was to be found in them. You will be amused at the following passage, where he intends to show that what the Oxford philosophers studied was not "ordinary language" at all: 4

"I will illustrate this by a fable. The Professor of Mental Philosophy, when called by his
bedmaker one morning, developed a dangerous frenzy, and had to be taken away by
the police in an ambulance... It happened that I, who live on the professor's staircase,
overheard the following dialogue between the bedmaker and the policeman:

Policeman:

'Ere, I want a word with yer.

Bedmaker:

Policeman:

What do you mean - - "A word"? I ain't done nothing

Ah, that's just it. Yer ought to 'ave done something. Couldn't yer see that the poor gentleman was mental?

Bedmaker: That I could. For an 'ole hour 'e went on something chronic. But when they're mental yer can't make them understand. 
In this little dialogue, 'word', 'mean', 'mental', and 'chronic' are all used in accordance with common usage. They are not so used in the pages of Mind by those who pretend that common usage is what they believe in... What they believe in is the usage of persons who have their amount of education, neither more nor less. Less is illiteracy, more is pedantry - so we are given to understand."

This gibe by Russell is in the same vein as the, much less bitter, quip by Quine at an Oxford dinner table, where, reportedly, he remarked something like: "And from now on in future, whenever I hear ordinary language spoken, I shall think of Oxford."

Russell's disdain for natural language went so far that for many years he actually believed that natural language could be exchanged for a mathematical logical language. The following passage bears clear witness to his serious underestimation of the wonderful complexity of nature: 5

"I am allowed to use plain English because everybody knows that I could use mathematical logic if I chose. Take the statement: 'Some people marry their deceased wives' sisters.' I can express this in language which only becomes intelligible after years of study, and this gives me freedom."

Despite the typical, and mildly amusing, Russell touch, there is an iron first in the velvet glove. The whole movement of logical analysis in the 20th century developed in a context of deep-rooted mistrust with regard to the human mind, the context of neo-positivism. In this context, the 'human factor' was, and often still is, considered an element of unreability, to be eliminated as much as possible by the application of a, hopefully infallible, formal or even mechanical device. The man-machinc opposition is a natural part of the strictly formal approach. But if we intend to penetrate into the buman mechanism, no matter its imputed "unreliability", this opposition becomes irrelevant.

The pioneers of formal semantics, Carnap, Davidson, Montague, took a less dim view of the logical properties of natural language. They took it, in principle, that natural language is a formal language, of the type used in modern quantification theory (with intensions), as we have said. They moved the demarcation line up in our direction, giving language more logical credit than their predecessors did, and relegating less to contaminated nature. But they were as unruffled as the older logicians were as regards refractory intuitions. The fact was, of course, that they took no interest in what we have called the "human mechanism". Carnap's application of lo- 
gical semantics to natural language was inspired by the wish to replace natural language by a better and more reliable vehicle of communication, Russell's pipedream, that is. And Davidson and Montague never developed a coherent epistemological basis for their work. They simply judged the logical contents of language interesting enough for a formal theory. It may sound unkind, but one feels tempted to say that for them language was indeed little more than a playground, with some interesting handicaps.

We, however, wo investigate the ecology of language, we wish to get a precise and adequate notion of the workings of the human mind, and we are therefore inclined to demand of our theories that they account not only for whatever in the way of standardly accepted 'sound' logic is to be found in natural language, but also, and with equal emphasis, for the phenomena that are, in the eyes of the formal semanticists, logically deviant, and even for the errors that occur. For us, whatever is part of the way we understand sentences falls legitimately under semantics. Our empirical question is: "How come we understand sentences the way we do?", and not the formal semanticists' question: „How can truth-conditions be computed from sentence structures?". We do not deny the importance or relevance of the formal semantics approach: the question of "getting truth-conditions and entailments right" is of central importance. For that reason we cannot go along with the skewing of observations to make them fit the logical-mathematical mould, standardly found in the writings of formal semanticists and their (linguistic) allies. But, on the other hand, it seems wrong to let the truthconditional aspect have absolute monopoly.

6.

It is clearly not so that formal semanticists rigidly stick to a fixed set of formalisms. To say that would be unfair and untrue. The movement from strict mathematical abstractness towards the reality of language, and the consequent re-evaluation of linguistic phenomena that marked the birth of formal semantics is still going on, if not accelerating. Formal semantics is, fortunately, becoming more and more flexible. Today one finds a certain willingness to reconsider, in particular, the traditional equation of the classical truth-functional propositional operators with their natural language counterparts. A sizeable amount of literature is available now on the logical properties of natural language implication, - clearly the most refractory of 
the classical set of four. ${ }^{6}$ Other examples are easy to give: fuzzy logics, nonmonotone logics, data-semantics are all developed with a view to rendering justice to the facts of language. Yet there still is a feeling that, despite all these attempts, the ecologists and the formalists still live in different worlds. There is as yet no, or hardly any, reaching of hands. Let us therefore see if we can succeed in analysing this situation to some extent.

The general factor behind the still existing opposition between formalists and ecologists is perhaps best characterized as paradigm loyalty on the part of the formal semanticists. It manifests itself in a variety of ways. First we notice a general reluctance to break away from the classical axioms, in particular the axiom of bivalence, i.e., the assumption of just two truthvalues and no room for truth-value gaps (the Principle of the Excluded Third). There is a reluctance generally to depart from tradition: 'deviant' logical analyses are felt to be concessions, rather than conquests. But the reluctance gets stronger as one gets closer to the core. The bivalence principle, already defended by Russell against the dangers that seemed to come from natural language (he devised his Theory of Descriptions for precisely that reason), seems particularly dear to the formal semanticists' heart. How else are we to explain the (uncritical) eagerness with which Wilson's (1975) and Boër \& Lycan's (1976) analysis of presuppositions was accepted in formal semantics? (This analysis reduces presuppositions to entailments within the limits of a classical system, and relegates whatever is felt to be "presuppositional" to pragmatics.) The ready acceptance of this analysis stands in stark contrast with the resistance met be so-called 'semantic' analyses of presuppositions, which invariably require an infringement of the bivalence principle, - even though such analyses provide a notably better fit with the facts.

Much in the same vein one finds a tendency to equate meaning description with truth-conditional description. A striking demonstration of this tendency is given by Cresswell, certainly not the least, nor the least ecologically interested one, among formal semanticists, in his recent book on Structured Meanings (1985), where he writes (p. 74):

6 See, e.g., the recent PhD-thesis by Veltman (1985), where a serious attempt is made at doing justice to the natural language facts of conditionals. Yet, amazingly, the same author still defends the incredible view that speakers should be educated towards "adopting" the best logic devised by logicians so far (p. 3), and that "whether a given logic is better than some alternative has little to do with its better fitting the facts; it is more a question of efficacy." (ib.) This goes to show how deep-rooted the methodological premises are. 
“... it seems to me that the meaning of $\sim$ is completely exhausted by its truthconditional description. I find it very odd to imagine that $\sim$ is a propositional operator whose meaning I only partially know."

Some analysts, of a more ecological persuasion, do not find it at all odd that natural language negation has semantic properties way beyond the (classical) truth-conditional description envisaged by Cresswell (Horn 1985; Seuren 1985).

Another manifestation of paradigm loyalty is found in what we may call a general mathematical way of thinking, as opposed to a linguistic way of thinking. This appears not only in the implicity accepted view that formal semantics is, and should be, cumulative: what has been established has been established, and recantations are not on. This may be a correct attitude as regards proofs, but it cannot without disaster apply to empirical applications of proofs, which is why empirical sciences are not cumulative. But apart from this methodological aspect, there are mathematical generalizations that go against the grain of language. This is perhaps best illustrated with an example.

In set theory, relations are considered interesting when they are transitive, and/or symmetrical and/or reflexive. ${ }^{7}$ If a relation $\mathrm{R}$ is both transitive and symmetrical, it is also reflexive. ${ }^{8}$ Now consider the relation "Parallel" $(\mathrm{P})$, defined over lines in a geometrical space. In order to capture important entailments it is desirable that $\mathrm{P}$ is classified as transitive: if $\mathrm{a}$ is parallel to $\mathrm{b}$, and $b$ is parallel to $c$, then $a$ is parallel to c. $P$ must also be characterized as symmetrical: for all lines $a$ and $b$, if $P(a, b)$ then $P(b, a)$. Given this, it follows that $\mathrm{P}$ must be reflexive: every line must be taken to be parallel to itself. In mathematics this is nothing but an innocent distortion of linguistic usage, which is of no further consequence. But trouble arises when transitivity, symmetry and reflexivity are considered properties of the relation denoted by the linguistic term parallel, or any other predicate with analogous properties, such as colleague, sibling, or belong to the same group as. For it is observationally wrong to say that sentences like:

(1) a. All lines are parallel to themselves.

b. All collegiate workers are colleagues of themselves.

$7 \quad$ A relation $R$ is transitive just in case, for all $a, b, c$, if $(R(a, b)$ and $R(b, c)$, then $R(a, c)$. $R$ is symmetrical if, for all $a, b$, if $R(a, b)$ then $R(b, a)$. $R$ is reflexive if, for all $a, R(a, a)$. The proof is simple: if $R$ is transitive and symmetrical, then, for all $a, b$, if $R(a, b)$ then, because of symmetry, also $R(b, a)$, and hence, because of transitivity, $R(a, a)$. 
c. All people are siblings of themselves.

d. Everyone belongs to the same group as himself.

are analytically true. Or, to put it differently: I am not my own brother, nor my own colleague. To say that I am is a distortion of the meanings of the words brother and colleague.

What are we to do about this? The formal semanticist will be inclined to disregard this discrepancy with the facts of language in his semantic description of the predicates concerned. For him, this will be an impurity of language, not of his system. The ecologist, however, must take this discrepancy seriously. He cannot deny the mathematical validity of the theorems of set theory: if a relation is both transitive and symmetrical, it is also reflexive. Since these relations are not reflexive, they cannot be both transitive and symmetrical. In fact, the formally correct conclusion is that they are not transitive. This conclusion is correct, since it is not so that if I am a colleague of Jones, and, therefore, Jones is a colleague of mine, I am a colleague of myself. Yet the ecologist is as little inclined as the formal semanticist is to lose hold of all the entailments that accrue from whatever is, undeniably, transitive about these relations. He wants, as it were, to eat his cake and have it. The way out of this dilemma seems to be given by the strategy of making systematic observations about this category of facts and, subsequently, trying to formulate sound but mathematically unorthodox notions that capture the facts as they really are. It is a striking fact of experience that such a strategy invariably turns out to be fruitful: what is discovered is not "contaminated nature", but an intricate and wonderful system. In this case, such a research strategy is likely to concentrate on phenomena of reflexivity, in grammar as well as in semantics, and it will yield a principled explanation of the fact that, for ordinary language users, sentences like:

(2) a. I shave all and only the men in my village who do not shave themselves.

b. Everyone was angry with everyone, but at peace with himself.

are neither paradoxical nor contradictory. What is needed in formal semantic descriptions, it would seem, is a better feel for the applied aspects of the logic or mathematics employed.

Paradigm loyalty also appears in an unwillingness to consider solutions to semantic problems in terms of a postulated mental or cognitive apparatus. Such explanations seem natural to a psychologist or a linguist, but in formal semantics one feels, apparently, better at home with abstract mathe- 
matical constructs than with implementable specifications of cognitive processing apparatus. A clear example is provided by the opposition between the formal semanticist's construct of possible worlds on the one hand, and the psychologist's apparatus of mental representations on the other. Possible worlds were brought in specifically to solve problems of intensionality in the semantics of natural language. They enabled the formal semanticists to create an intensional logic by applying ordinary extensional logic to any number of possible worlds. Intensional phenomena in language are accounted for, in current formal semantic theories, entirely in terms of set theory and functions over possible worlds. Such an account can hardly fail to be unpopular with psychologists, given the utter implausibility of such functions in any psychological theory. Psychologists have recently argued that any theory of mental calculus requires the notion of mental representations: no calculus without representations (cp. Fodor 1981). It then appeared that a system of mental representations, if properly formulated, has the explanatory potential required for intensionality phenomena in language (cp. Seuren 1985 , ch. 5). Clearly, an account of intensionality phenomena in terms of a system of embedded representations ("discourse domains") is empirically superior to an account in terms of unimplementable functions over possible worlds. We now see that Cresswell (1985, ch. 6) rejects any semantic explanation in terms of mental representations, but his argument can hardly be said to cut ice. This obvious resistance to the introduction of internal representations cannot be based on any alleged logical incoherence of such a notion. It must derive from some sort of paradigm loyalty, ill-advised and unjustified as such a loyalty may be.

Such loyalty is the more remarkable if it is considered that the possible worlds type of formal semantics runs into some very serious problems as a result of the very construct of possible worlds, not of the facts to be explained. These problems are in part well-known and acknowledged by the formal semanticists themselves. Some such problems appear when infinite functions are involved that can be characterized only by enumeration, such as all referential functions (spread as they are over all possible worlds). Attempts have been made, notably by Russell (in his Theory of Descriptions) and by Quine (in his programme of elimination of particulars), to get rid of reference altogether, but it is now generally agreed that such attempts have failed. Formal semantics is, therefore, saddled with these functions. In an ecologically oriented methodology one might posit auxiliary cognitive mechanisms that will characterize referential functions to the extent that they need to be characterized. But, first, this strategy runs against the paradigm 
loyalty we have just discussed. And, secondly and more importantly, even so the system founders on account of its possible worlds.

Possible worlds may have looked like a white elephant to begin with, but they become an essential obstacle when logical necessity is involved, as in the case of proper names. In the standard formal semantics view (Kripke 1980), proper names necessarily refer to the same individual in all possible worlds. They differ from descriptively referring expressions in that their reference value is known for no matter which context, intensional or other, where they are used, once they are fixed onto one referent in one world. It follows that an adequate theory'of understanding and interpretation, an adequate semantics, that is, must specify for all possible worlds which individual is referred to by the name in question, clearly an impossible task. An analogous problem presents itself with necessary truths or falsehoods, which are deemed to be true, or false, in all possible worlds. Since semantic distinctions are all expressed in terms of different sets of possible worlds, it is impossible to make semantic distinctions between one necessary truth, or falsehood, and another, so that, for example, whoever believed one of them is forced, by this theory, to believe them all. This particular problem is widely acknowledged by formal semanticists (cp. Dowty et al. 1981. 175), and they worry a great deal about them (Cresswell 1985 came about as a result of this worry). Yet, we will still find that curious unwillingness to consider research strategies outside the established programmatic framework. One sticks explicity to the idea that intensional phenomena in language are to be accounted for exhaustively in terms of set theory and functions over possible worlds, and not, for example, with the help of 'intermediate' mental representations.

\section{7.}

I have, in the past few minutes, tried to give an idea of the kind of obstacles that stand in the way of a fruitful collaboration between ecologists and formalists, - obstacles that are mostly hidden from the surface and are, therefore, treacherous. I have been critical of the formalist paradigm in its present manifestations. But it has not been my intention to advise against such a collaboration. On the contrary, we, ecologists, have an enormous amount to learn from the formal semanticists, who have made absolutely essential steps forward in the direction of the clarification of hitherto nebulous notions of meaning and interpretation, and have thus provided at least 
one opening towards a further and better insight into the nature of the central intelligent functions of man. My purpose has been a positive one: to incite psychologists and linguists alike to get acquainted with what formal semantics has to offer, while being aware of the pitfalls and blind alleys.

\section{REFERENCES}

BOËR S. and W. LyCAN (1976), The myth of semantic presupposition. Indiana University Linguistics Club.

Cresswell, M. J. (1985), Structured meanings: the semantics of propositional attitudes. M.I. T. Press: Cambridge, Mass.

Dowty, D.R., R.E. WAll, S. Peters (1981), Introduction to Montague semantics. Reidel: Dordrecht.

FoDor, J.A. (1981), Representations. Philosophical essays on the foundations of cognitive science. Harvester Press: Brighton.

Fodor, J.A. (1983), The modularity of mind. M.I.T. Press: Cambridge, Mass.

Gazdar, G., E. Klein, G. Pullum, I. Sag (1985), Generalized Phrase Structure Grammar. Blackwell: Oxford.

Horn, L.R. (1985), Metalinguistic negation and pragmatic ambiguity. Language 61.1, $121-174$.

KrIPKE, S. (1980), Naming and necessity. Blackwell: Oxford.

Russell, B. (1956), Portraits from memory and other essays. Allen \& Unwin: London.

Seuren, P. A. M. (1978), Grammar as an underground process: In: Sinclair et al., 201-223.

Seuren, P. A. M. (1985), Discourse semantics. Blackwell: Oxford.

Sinclair, A., R. J. Jarvella, W. J. M. Levelt (eds.) (1978), The child's conception of language. Springer: Berlin.

Veliman, F. (1985): Logics for conditionals. PhD-thesis, Amsterdam University.

Wilson, D. (1975), Presuppositions and non-truth-conditional semantics. Academic Press: London-New York-San Francisco. 